Original Research Paper

\title{
Variety Trial on Tomato Hybrids in Greenhouse Conditions of the Prearal Area of Kazakhstan
}

\author{
${ }^{1}$ Elina Bakhtiyarovna Dyamurshayeva, \\ ${ }^{1}$ Rakhym Iskendirovich Kudiyarov, ${ }^{2}$ Igor Aleksandrovich Bobrenko, \\ ${ }^{3}$ Gulsym Zykriyaevna Sauytbayeva, ${ }^{1}$ Nurlan Zhetkergenovich Urazbayev, \\ ${ }^{1}$ Galina Evgenyevna Dyamurshayeva and ${ }^{1}$ Salima Izbaskanovna Sadybekova \\ ${ }^{1}$ Korkyt Ata Kyzylorda State University, Kyzylorda, Kazakhstan \\ 120014 Kazakhstan, Kyzylorda Region, Kyzylorda city, Ayteke bi St., 29a, Kazakhstan \\ ${ }^{2}$ P.A. Stolypin Omsk State Agricultural University, Omsk, Russia, \\ 644008 Russia, Siberian Federal District, Omsk region, Omsk city, Institute Square, Russia \\ ${ }^{3}$ Humanitarian and Technical Institute "Akmeshit", Kyzylorda, Kazakhstan \\ 120000 Kazakhstan, Kyzylorda region, Kyzylorda city, Muratbayev St., 43, Kazakhstan
}

Article history

Received: 14-01-2017

Revised: 06-04-2017

Accepted: 08-04-2017

\section{Corresponding Author:}

Elina Bakhtiyarovna

Dyamurshayeva

Korkyt Ata Kyzylorda State

University, Kyzylorda,

Kazakhstan

120014 Kazakhstan, Kyzylorda

Region, Kyzylorda city, Ayteke

bi St., 29a, Kazakhstan

Email: korkyt.green@mail.ru

\begin{abstract}
One of the most important factors in the intensification of greenhouse tomato production is the introduction of new high-yielding hybrids which are adapted to new technologies and unfavorable climatic conditions. The present investigation was carried out in the Korkyt Ata Kyzylorda State University greenhouse between 2010 and 2015, to study the performance of different tomato hybrids in terms of growth, yield and quality inside the greenhouse in the PreAral area conditions in Kazakhstan. Seventeen tomato hybrids selected from the Netherlands, Israel and Russia were grown on a substrate of sawdust in the conditions of the extended culture. Based on the results obtained, the most productive hybrids and those best adapted to the climatic conditions of the area are identified and the fruits' quality assessment and cost-effectiveness analysis are given. The best yield and fruit quality results were obtained from hybrids from the Dutch selection. The best variety for all indicators - productivity, yield of standard products, fruit taste and largest profit - was the Panekra hybrid. Lilos F1, Maxitos F1, Gravitet F1, Klepton F1, Esmira F1 and Clarabella F1 hybrids also had high productivity, good fruit quality and relatively high profit. These hybrids are recommended for greenhouse soilless culture in PreAral area conditions.
\end{abstract}

Keywords: Greenhouse, Soilless Culture, Tomato Hybrids, Productivity and Quality, Economic Efficiency

\section{Introduction}

Today, tomato (Solanum lycopersicum L.) is one of the most important members of the nightshade family that are widely grown in many countries across the globe. It is recognized as an important commercial and dietary vegetable crop and occupies a prominent position among vegetables due to its export value (Singh et al., 2014).

However, as economic matters currently stand, greenhouse facilities for vegetables production can be profitable for obtaining high stable yields with simultaneous cost reduction which is very high and is constantly increasing, mainly due to significant energy costs (Brovko, 2006; Rodica et al., 2015).
One of the most important factors in the intensification of greenhouse tomato production is the introduction of new high-yielding varieties and hybrids which have complex resistance to diseases and pests adapted to new technologies and unfavorable climatic conditions (Balashov, 2006; Korol, 2000; Gavrish, 2015).

Up-to-date industrial greenhouse production impos esexclusive standards on varieties and hybrids. They must not only behighly-yielding, but also have a high consumer appeal determining the priority of outlets sales (Korol, 2000; Barabash and Kravchenko, 2012).

Many researchers note the enormous importance of variety in getting high yield of vegetables in the 
protected ground. They argue that a variety (hybrid) is one of the most significant components of science-based production and a major part of any technology, since the cultivation system, energy and other operational expenses are in close relation to the crop varietal factors (Tarakanov, 1997; Korol, 2011; Becherescu et al., 2015; Bakulina, 1996).

Technology and variety are closely linked: The greater the intensity of technology and the greater investment in crop cultivation, the more important the variety (Bakulina, 1998).

A variety must be processable and its genotype must provide a sufficient degree of reliability and protection from the adverse effects of biotic and abiotic environmental factors. Together they define the desired level of productivity (Shevelukha, 1992).

In the last decade, a soilless technology of vegetable crop cultivation was widely practiced in the world, ensuring efficient use of all the resources for maximum yield of high-quality vegetable production even in areas with unfavorable climatic conditions (Jensen, 1997; Dorais et al., 2001).

At the same time, the most important reserve of yield growth is a more complete realization of the productivity potential of cultivated hybrids adapted not only both for the given technology but also and for the climatic conditions of a particular region (Lutsenko, 2002; Kiry, 2007). Generally, crops are not profitable unless they are adapted to the region in which they are produced (Reddy et al., 1999).

The range of greenhouse tomato seeds is constantly changing as the leading plant breeding and seed companies deliver a large range of vegetable crops hybrids the market every year and the selection of a tomato cultivar for hydroponic production in greenhouses or other protected cultures has become a much more complex decision. Making the correct cultivar choices and implementing the appropriate production and trellis systems are critical to success (Hochmuth, 2015).

Soilless tomato production technology in greenhouses is not popularized yet in the PreAral region, where there is wide scope for expansion and production potential. Therefore, testing and searching for new highyielding models for these growing conditions remains necessary. The present investigation was undertaken to study the performance of different tomato hybrids in terms of growth, yield and quality in the greenhouse conditions of the PreAral area.

\section{Materials and Methods}

Research was carried out in the greenhouses of the Korkyt Ata Kyzylorda State University in 2010-2015. The studies included the consistent implementation of laboratory, semi-industrial and industrial experiments using standard ones for experiments on vegetable crops in the protected ground structures (Belik, 1992; Dospechov, 1979).

Since currently all the greenhouse production of vegetables in Kazakhstan is based on the cultivation of foreign selection hybrids, the indeterminate tomato hybrids from the Dutch selection: Lilos F1, Sample F1, Favorita F1, Grace F1, Clarabella F1, Abellus F1, Klepton F1, Maxitos F1, Esmira F1, Gravitet F1, Panekra F1, of Israel: Sharlotta F1, Garem F1 and of Russia: Kalash F1, Azov F1, Beysuzhok F1, Salakhutdin F1 were chosen as the objects of the study. As the standard sample, a hybrid Franchesca F1 (Israeli selection) which had very good previous results in terms of crop productivity and quality was planted for the entire study period. The experiment was set out in a randomized complete block design with three replications.

The studied hybrids grew on wood sawdust, which is widely used as a substratum for the cultivation of vegetables in greenhouses (Gruda and Schnitzler, 2004; Dorais et al., 2007; Ehret and Helmer, 2009).

Presently, the most popular combination of applying the small-volume hydroponics to grow tomatoes in greenhouses is the extended one (January-November).

However, the climatic conditions of the Aral region are not favorable for running the culture of tomatoes in greenhouse in summer period characterized by high temperatures (above $45^{\circ} \mathrm{C}$ ) and low air humidity (less than $10 \%$ ), so a new crop combination with due account of these climatic features was proposed: Sowing of seeds on July 15th, planting of seedlings on September 10th, end of cultivation on July 1st (Fig. 1).

Tomato seedlings were grown in pots prickling-out $\varnothing$ $10 \mathrm{~cm}$ and peat substrate $(\mathrm{pH} \mathrm{5,5-6,0)}$. The seedlings were fed using solutions of complex fertilizers containing N:P:K 10-52-10 and 14:11:25 and sodium humate and lime saltpeter (EC 1.0-5.0).

In phase 4 the plants were set out in the greenhouses and in the phases 8 and 9 the seedlings were mixed with a substrate pre-moistened with nutrient solution EC -3.03.5 via a drip irrigation system. The standing density of plants in greenhouse was of $2,3 \mathrm{p} / \mathrm{m}^{2}$. Tomato plants formed in one stem with half-staffing and racking.

Temperature requirements were maintained in accordance with the technological requirements for tomato cultivation (Table 1).

Plant nutrition was carried out using a nutrient solution fully balanced on the plant food compound and differentiated according to the maturity series of the plant (Table 2).

Watering and plant nutrition were conducted by dripping every hour from 7.00 to 17.00 so that a certain percentage of the nutrient solution was withdrawn from the substrate through drainage in each irrigation (Table 3).

Water application and nutrition rates were adjusted according to the testimony of the $\mathrm{EC}$ and the $\mathrm{pH}$ of the nutrient and drainage solutions. 


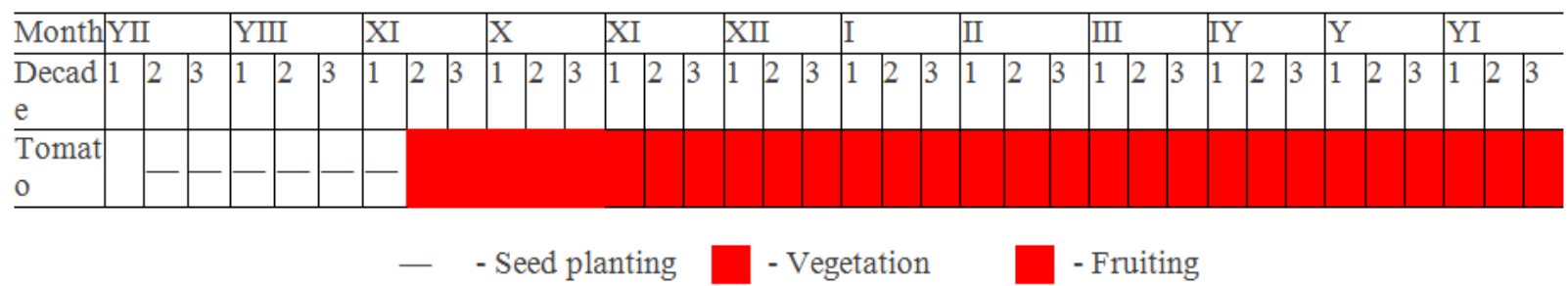

Fig. 1. Crop combination of tomatoes in the winter greenhouse

Table 1. Temperature requirements for tomato cultivation in greenhouse

During the day

\begin{tabular}{llll} 
Cropping season & In sunny weather & In cloudy weather & At night \\
\hline Before fruiting & $20-22^{\circ} \mathrm{C}$ & $19-20^{\circ} \mathrm{C}$ & $15-17^{\circ} \mathrm{C}$ \\
Fruiting & $24-26^{\circ} \mathrm{C}$ & $20-22^{\circ} \mathrm{C}$ & $17-18^{\circ} \mathrm{C}$ \\
\hline
\end{tabular}

Table 2. Mineral composition for growing tomatoes on a substrate (Olericulture, 2001) Food compounds

\begin{tabular}{|c|c|c|c|c|c|c|c|c|c|c|c|}
\hline \multirow[b]{2}{*}{ Cropping season } & \\
\hline & $\mathrm{N}$ & $\mathrm{P}$ & $\mathrm{K}$ & $\mathrm{Ca}$ & $\mathrm{Mg}$ & $\mathrm{Fe}$ & $\mathrm{Cu}$ & Mo & $\mathrm{Mn}$ & $\mathrm{Zn}$ & $\mathrm{B}$ \\
\hline Before fruiting & 107 & 114 & 114 & 38 & 20 & 0,25 & 0,018 & 0,004 & 0,15 & 0.012 & 0.034 \\
\hline Fruiting & 200 & 55 & 300 & 200 & 55 & 3.00 & 0.50 & 0.12 & 0.12 & 0.20 & 0.90 \\
\hline
\end{tabular}

Table 3. Recommended amount of drainage at different watering time

\begin{tabular}{lllllllll}
\hline Time & 7.00 & 9.00 & 10.00 & 11.00 & 12.00 & 13.00 & 15.00 & 17.00 \\
\hline Amount of drainage, $\%$ & 0 & 3 & 6 & 12 & 30 & 25 & 25 & 10 \\
\hline
\end{tabular}

During the cropping season the conducted measures were as follows:

- Phenological observations of plant growth and development with the establishment of terms and emergence of seedlings, the hilling time, the early flowering, fruiting and the late vegetation period

- Biometric measurements of the phases of development of 4 fixed plants in each plot, with determination of height of laying the brush, the number of bunches and fruits and the mass of fruit

- Registration of the main indicators of the microclimate

- Monitoring of watering and plant nutrition

- Collection and analysis of the crop quality

For evaluation of quality parameters, ripe, firm and uniform tomatoes were chosen. The following measurements were done: Shape, weight, firmness, flavor intensity (GOST 1725-85), dry matter content (GOST ISO 2173-2013), total sugar content (GOST 8756.13-87), titratable acidity (GOST ISO 750-2013), ascorbic acid concentration (GOST 24556-89) and nitrate ions content (GOST 29270-95).

Mathematical processing of yield data was performed by an analysis of variance methods (Dospechov, 1979) using the computer program Excel from the Microsoft Windows host operating system.
The economic efficiency of tomato production was also worked out by considering the current price of inputs and produce.

\section{Results}

The results of phenological observations have shown that under growth in the conditions of the 7th photic zone of the pre-Aral area the investigated hybrids had different adaptive properties which were defined as the intensity of their growth and development processes (Table 4).

In general, the biological features of the studied tomato hybrids and their adaptation to the cultivation conditions have had a direct impact on their productivity (Table 5).

To test the statistical null hypothesis $\mathrm{HO}$ on the availability of the significant differences in the productivity of the studied tomato hybrids and validation of the obtained results, an analysis of the variance of their productivity results was performed. The results of mathematical processing have allowed to claim that the investigated hybrids differed from each other in terms of productivity (early - Ff $>$ F05 $=10.25>1.5$, total $-\mathrm{Ff}>\mathrm{F} 05=113.91>1.5$ ).

Since recent times, in the case of hybrid assessment, along with the main criterion-productivity, visual appeal, taste and ecological purity of fruits are also of important value. Therefore, the study of the tomato hybrids collection covered the organoleptic assessment and biochemical analysis of the fruit (Table 6). 
Table 4. Characteristics of growth and development of tomato hybrids in the extended cycle

\begin{tabular}{|c|c|c|c|c|c|}
\hline \multirow[b]{2}{*}{ Hybrids } & \multicolumn{5}{|c|}{ Period duration, number of days } \\
\hline & $\begin{array}{l}\text { From pre-emergence } \\
\text { growth to } \\
\text { pre-blossom }\end{array}$ & $\begin{array}{l}\text { From } \\
\text { pre-emergence } \\
\text { growth to fruiting }\end{array}$ & $\begin{array}{l}\text { Number of } \\
\text { leaves before the } \\
\text { first blossom, piece }\end{array}$ & $\begin{array}{l}\text { Average amount } \\
\text { of fruit on 1-3 } \\
\text { inflorescence, piece }\end{array}$ & $\begin{array}{l}\text { Fruit } \\
\text { weight, } g\end{array}$ \\
\hline \multicolumn{6}{|l|}{ Dutch selection } \\
\hline Lilos F1 & $41-43$ & $98-102$ & 9 & 8 & 126 \\
\hline Sample F1 & $43-45$ & $106-108$ & 10 & 8 & 124 \\
\hline Favorita F1 & $42-44$ & $102-104$ & 9 & 8 & 113 \\
\hline Grace F1 & $43-45$ & $106-108$ & 10 & 8 & 129 \\
\hline Clarabella F1 & $46-48$ & $112-114$ & 10 & 8 & 122 \\
\hline Abellus F1 & $41-44$ & $100-103$ & 9 & 8 & 121 \\
\hline Klepton F1 & $42-45$ & $103-105$ & 9 & 8 & 124 \\
\hline Maxitos F1 & 42 & 101 & 9 & 6 & 142 \\
\hline Esmira F1 & 42 & 101 & 9 & 8 & 126 \\
\hline Gravitet F1 & 42 & 100 & 9 & 8 & 110 \\
\hline Panekra F1 & 42 & 101 & 9 & 6 & 160 \\
\hline \multicolumn{6}{|l|}{ Israel selection } \\
\hline Sharlotta F1 & 41 & $102-104$ & 8 & 10 & 91 \\
\hline Garem F1 & 41 & $100-102$ & 8 & 9 & 106 \\
\hline Franchesca F1 st & $46-48$ & $111-116$ & 9 & 7 & 133 \\
\hline \multicolumn{6}{|l|}{ Russian selection } \\
\hline Kalash F1 & $39-41$ & 102 & 8 & 8 & 110 \\
\hline Azov F1 & $39-41$ & 102 & 8 & 12 & 79 \\
\hline Beysuzhok F1 & $39-41$ & 102 & 8 & 10 & 95 \\
\hline Salakhutdin F1 & $39-41$ & 102 & 8 & 10 & 100 \\
\hline
\end{tabular}

Table 5. Yield of promising tomato hybrids and product quality in the extended cycle

\begin{tabular}{|c|c|c|c|c|c|c|}
\hline \multirow[b]{3}{*}{ Hybrid } & \multicolumn{6}{|l|}{ Yield } \\
\hline & \multicolumn{2}{|l|}{ Early } & \multicolumn{2}{|l|}{ Total } & \multicolumn{2}{|c|}{ Standard } \\
\hline & $\mathrm{kg} / \mathrm{m}^{2}$ & $\%$ to $\mathrm{St}$ & $\mathrm{kg} / \mathrm{m}^{2}$ & $\%$ to $\mathrm{St}$ & $\mathrm{kg} / \mathrm{m}^{2}$ & $\%$ to total yield \\
\hline \multicolumn{7}{|l|}{$\overline{\text { Dutch selection }}$} \\
\hline Lilos F1 & 2.07 & 94.5 & 23.86 & 91.2 & 23.12 & 96.9 \\
\hline Sample F1 & 2.04 & 93.6 & 21.85 & 83.6 & 20.54 & 94.0 \\
\hline Favorita F1 & 1.35 & 61.9 & 19.63 & 75.1 & 18.22 & 92.8 \\
\hline Grace F1 & 1.22 & 56.0 & 23.08 & 88.3 & 22.27 & 96.5 \\
\hline Clarabella F1 & 2.11 & 96.8 & 26.13 & 99.9 & 25.48 & 97.5 \\
\hline Abellus F1 & 1.93 & 88.5 & 22.43 & 85.8 & 21.71 & 96.8 \\
\hline Klepton F1 & 1.87 & 85.8 & 24.30 & 93.0 & 23.50 & 96.7 \\
\hline Maxitos F1 & 2.14 & 98.2 & 23.90 & 91.4 & 23.33 & 97.6 \\
\hline Esmira F1 & 2.23 & 102.3 & 24.72 & 94.6 & 24.18 & 97.8 \\
\hline Gravitet F1 & 1.75 & 80.3 & 24.29 & 92.9 & 23.22 & 95.6 \\
\hline Panekra F1 & 2.16 & 99.1 & 27.30 & 104.4 & 26.73 & 97.9 \\
\hline \multicolumn{7}{|l|}{ Israel selection } \\
\hline Sharlotta F1 & 1.66 & 76.1 & 17.94 & 68.6 & 16.40 & 91.4 \\
\hline Garem F1 & 1.60 & 73.4 & 21.45 & 82.1 & 20.14 & 93.9 \\
\hline Franchesca F1 St & 2.18 & 100.0 & 26.14 & 100.0 & 25.41 & 97.2 \\
\hline \multicolumn{7}{|l|}{ Russian selection } \\
\hline Kalash F1 & 1.40 & 64.2 & 20.70 & 79.2 & 18.71 & 90.4 \\
\hline Azov F1 & 1.33 & 61.0 & 15.62 & 59.7 & 13.46 & 86.2 \\
\hline Beysuzhok F1 & 1.52 & 69.7 & 19.50 & 74.6 & 17.37 & 89.1 \\
\hline Salakhutdin F1 & 1.38 & 63.3 & 20.31 & 77.7 & 18.56 & 91.4 \\
\hline $\mathrm{LED}_{05}$ & 0.03 & 3.4 & 0.45 & 2.0 & & \\
\hline
\end{tabular}

In the course of the research the total production costs of tomatoes in soilless culture totaled to 6332.83 $\mathrm{KZT} / \mathrm{m}^{2}$.

When growing tomato plants in the extended cycle, a term of their growing season is much longer. Due to the fact that the cropping and sale of greenhouse tomatoes are stretched in time, sales prices during the period of fruiting are significantly different. Maximum price for tomatoes fruit was in the period from December to March and amounted to $350-400 \mathrm{KZT} / \mathrm{kg}$, minimum $200 \mathrm{KZT} / \mathrm{kg}$ in April and in the rest of the time the price was $250-300 \mathrm{KZT} / \mathrm{kg}$. 
Elina Bakhtiyarovna Dyamurshayeva et al. / OnLine Journal of Biological Sciences 2017, 17 (2): 26.34 DOI: $10.3844 /$ jbsci.2017.26.34

\begin{tabular}{llllll}
\hline \multicolumn{2}{l}{ Table 6. Biochemical structure of tomato fruits } & & & & \\
\hline Hybrid & $\begin{array}{l}\text { Dry } \\
\text { matter, \% }\end{array}$ & $\begin{array}{l}\text { Total } \\
\text { sugar, } \%\end{array}$ & $\begin{array}{l}\text { Askorbic } \\
\text { acid, mg/100 g }\end{array}$ & $\begin{array}{l}\text { Titratable } \\
\text { acidity, } \%\end{array}$ & $\begin{array}{l}\text { Nitrate } \\
\left(\mathrm{NO} 3^{-}\right), \mathrm{mg} / \mathrm{kg}\end{array}$ \\
\hline Dutch selection & & & & & \\
Lilos F1 & 6.2 & 2.91 & 15.38 & 0.59 & 84.6 \\
Sample F1 & 5.8 & 2.67 & 14.42 & 0.53 & 91.2 \\
Favorita F1 & 5.4 & 2.52 & 14.61 & 0.57 & 93.5 \\
Grace F1 & 5.9 & 2.83 & 15.79 & 0.60 & 87.2 \\
Clarabella F1 & 6.5 & 2.97 & 16.25 & 0.60 & 83.1 \\
Abellus F1 & 5.9 & 2.66 & 15.92 & 0.55 & 90.4 \\
Klepton F1 & 6.2 & 2.86 & 15.29 & 0.58 & 84.0 \\
Maxitos F1 & 6.0 & 3.01 & 15.42 & 0.61 & 85.6 \\
Esmira F1 & 5.9 & 2.79 & 16.07 & 0.57 & 89.5 \\
Gravitet F1 & 6.1 & 2.75 & 15.83 & 0.56 & 87.2 \\
Panekra F1 & 6.3 & 3.17 & 16.17 & 0.59 & 85.3 \\
Israel selection & & & & 0.54 & 96.5 \\
Sharlotta F1 & 5.4 & 2.71 & 14.72 & 0.51 & 91.2 \\
Garem F1 & 5.6 & 2.62 & 14.86 & 0.57 & 84.9 \\
Francesca F1 St & 6.4 & 2.96 & 15.89 & & 93.7 \\
Russian selection & & & & 0.51 & 98.5 \\
Kalash F1 & 5.7 & 2.52 & 14.70 & 0.58 & 96.4 \\
Azov F1 & 5.2 & 2.35 & 14.42 & 0.52 & 94.1 \\
Beysuzhok F1 & 5.5 & 2.53 & 14.88 & 0.52 & \\
Salakhutdin F1 & 5.6 & 2.58 & & &
\end{tabular}

Table 7. Economic efficiency of tomato hybrids

\begin{tabular}{|c|c|c|c|c|}
\hline Hybrid & $\begin{array}{l}\text { Weighted average } \\
\text { price, KZT/kg }\end{array}$ & $\begin{array}{l}\text { Sales proceeds, } \\
\mathrm{KZT} / \mathrm{m}^{2}\end{array}$ & $\begin{array}{l}\text { Profit, } \\
\mathrm{KZT} / \mathrm{m}^{2}\end{array}$ & $\begin{array}{l}\text { Cost-benefit } \\
\%\end{array}$ \\
\hline \multicolumn{5}{|l|}{ Dutch selection } \\
\hline Lilos F1 & 294.17 & 7018.89 & 686.07 & 10.8 \\
\hline Sample F1 & 290.42 & 6345.68 & 12.85 & 0.2 \\
\hline Favorita F1 & 292.16 & 5735.10 & -597.72 & - \\
\hline Grace F1 & 297.14 & 6857.99 & 525.16 & 8.3 \\
\hline Clarabella F1 & 303.96 & 7942.47 & 1609.64 & 25.4 \\
\hline Abellus F1 & 293.71 & 6587.91 & 255.08 & 4.0 \\
\hline Klepton F1 & 294.33 & 7152.22 & 819.39 & 12.9 \\
\hline Maxitos F1 & 296.86 & 7094.95 & 762.12 & 12.0 \\
\hline Esmira F1 & 298.02 & 7367.05 & 1034.22 & 16.3 \\
\hline Gravitet F1 & 295.59 & 7179.88 & 847.05 & 13.4 \\
\hline Panekra F1 & 300.66 & 8208.02 & 1875.19 & 29.6 \\
\hline \multicolumn{5}{|l|}{ Israel selection } \\
\hline Sharlotta F1 & 288.20 & 5170.31 & -1162.52 & - \\
\hline Garem F1 & 291.80 & 6259.11 & -73.72 & - \\
\hline Francesca F1 St & 302.28 & 7901.60 & 1568.77 & 24.7 \\
\hline \multicolumn{5}{|l|}{ Russian selection } \\
\hline Kalash F1 & 290.04 & 6003.83 & -329.00 & - \\
\hline Azov F1 & 284.38 & 4442.02 & -1890.81 & - \\
\hline Beysuzhok F1 & 287.54 & 5607.03 & -725.80 & - \\
\hline Salakhutdin F1 & 290.90 & 5908.19 & -424.65 & - \\
\hline
\end{tabular}

To evaluate the effectiveness of cultivation of tomato hybrids on the basis of the monthly sales prices there was calculation of the weighted average price for the whole season and an assessment of economic efficiency of the studied hybrids (Table 7).

\section{Discussion}

The most important reserve of growth of the cultivated hybrids yield is their environmental adaptability, determined by their biological characteristics and expressed in the plant's earliness and power, fruit size, its quality and of course, its overall productivity.

Rajasekar (2013) also reported the fact that growth, development, productivity and the post-harvest quality of any crop are heavily depend on the interaction between the plant genetics and the environmental conditions under which they are grown.

The results of phenological observations have shown that under growth in the conditions of the 7 th photic 
zone of the pre-Aral area, the investigated hybrids had different adaptive properties which were defined as the intensity of their growth and development processes.

Thus, the period from pre-emergence growth to preblossom was dependent on the location of the first inflorescence. Hybrids that formed the first bottom truss after the 8-leaf had the shortest period from preemergence growth to pre-blossom and it ranged from 39 to 41 days. Hybrids that formed the first bottom truss after the 9 and 10-leaf had the longest period and it ranged from 41 to 48 days.

Formation of the first cluster and its inflorescence occurs earlier than in hybrids from the Russian selection for Garem F1 Sharlotta F1 (Israeli selection) -39-41 days after pre-emergence growth. The latest inflorescence were the hybrids Frachesca F1 and Clarabella F1 -46-48 days after pre-emergence growth.

However, hybrids from the Dutch selection Lilos F1, Gravitet F1, Penelra F1, Esmira F1, Maxitos F1 and Israeli selection Garem F1, Favorita F1, with a period from germination to fruiting of 100-101 days, were the most mature by the fruiting time. Hybrids from the Russian selection started to bear fruit102 days after preemergence growth.

The latest-ripening hybrids were Franchesca F1 (standard sample) and hybrid Clarabella F1, whose fruiting respectively occurred on the 111-116th and 112114 th days after germination.

The pre-ruiting period for most hybrids began about 2 weeks earlier than for the standard sample and lasted 101-104 days after germination and for 2 F1 and Grace F1 Sample hybrids this period amounted to an intermediate value and lasted 106-108 days.

The early and late flowering is attributed as a genotypic character and somewhat influenced by environmental factors of particular growing areas. Hussain et al. (1990; Amarananjundeshwara et al., 2008) also reported similar findings for days to flower initiation on different tomato hybrids.

It is also considered to be an economically important trait and therefore, takes on significance for crop improvement programmers since the early flowering hybrids and varieties with high yield are usually sought after for commercial cultivation (Singh et al., 2014).

Hybrids Maxitos F1 and Panekra F1 were selected among the studied hybrids for the intensity of plant growth and development: Their fruiting occurred 10-15 days earlier than the standard ones and although they formed fewer fruits $(6$ pcs.) on the first three inflorescences in comparison with a standard one (7 pcs.), their weight was higher at 9 and $24 \mathrm{~g}$ respectively.

In addition, twohybrids can be distinguished amongst those studied: Lilos F1 and Esmira F, whose fruiting occurred in the early stages and formed 8 fairly large fruit on the first three inflorescences.
Less intense were hybrids from the Russian selection Kalash F1, Salakhutdin F1, Beysuzhok F1 and especially Azov F1. Although these hybrids' fruiting occurred in the early stages and the formation of the first bottom truss came after the 8-leaf, they formed small fruits.

According to the research the most productive hybrids were from the Dutch selection which were allocated by the early and total yield as follows: Panekra F1, Clarabella F1, Lilos F1, Klepton F1, Maxitos F1, Esmira F1 and Gravitet F1.

The early out-yield of hybrid Esmira F1 made up $2.3 \%$ and the yield of hybrids Panekra F1, Clarabella F1, Maxitos F1 was up to standard sample.

Hybrid Panekra F1 made up $4.4 \%$ by total standard out-yield, the yield of hybrid Clarabella F1 was the same as that of the standard sample and the yield of hybrids Lilos F1, Klepton F1, Maxitos F1, Esmira F1 and Gravitet F1 was $91.2 ; 93.0 ; 91.4 ; 94.6$ and $92.9 \%$ with respect to the check respectively.

Hybrids from the Russian and Israeli selection had a low performance. Their yields were much lower than those of the standard sample:

- The Russian breeding hybrids: The earliest - by $30.3-39.0 \%$ and the total - by $21.8-40.3 \%$

- $\quad$ The Israeli breeding hybrids: The earliest - by 38.1 and $23.9 \%$ and the total - by 24.9 and $31.4 \%$

The highest yield of standard products shows controlling hybrid Franchesca F1 (97.2\%) and the Dutch breeding hybrids (95.6-97.9\%), with the exception of the hybrids Sample F1 and Favorita F1 where the index was 94.0 and $92.8 \%$.

Whereas the plants of the studied hybrids of the Russian and Israeli selection formed small fruits, the output of standard products made up only 86.2 to $93.9 \%$.

Research revealed that tomato yield depended on two components viz., fruit weight and number of fruits per flower branch. These traits are quantitative and they are both determined by a number of genetic and environmental factors (Singh and Singh, 1985; Dhaliwal and Nnandpuri, 1988; Singh et al., 1989; Zdravković et al., 2011). Such genetic differences for marketable yield of tomato and other plant characters in different tomato genotypes had also been reported by (Hussain et al., 1990; 2001; Singh et al., 2006; 2009; 2014).

During the period of research, the following tendency was found: The more fruits per flower branch, the lower their average weight and vice versa. These findings reveal that the size of fruits, but not the number of fruits per plant will produce more yield than the hybrids bearing small and medium sized fruits that are greater in number. The highest yield was by hybrids from the Dutch selection, due to their good plant growth and quality parameters. These hybrids are sufficiently promising since 
the improvement of farming techniques in accordance with the varietal features can gain the yield.

As a result of the studies undertaken, it was found that the habit, smell and taste of the fruits of all investigated hybrids met the requirements of GOST. The fruits are whole, fresh, clean, healthy and dense, with the stem undamaged by pests and diseases, without mechanical damage and sunburn, with the smell and taste specific for the hybrid.

The density of the tomato fruit, assessed on a scale from 1 to 10 , was very good and made up 8.5-9.3. This hardness of the fruit is very beneficial for the market because the fruit can be harvested in the later stages of maturity and have the best taste.

However, the contents of the smaller fruits in some hybrids exceeded the permissible value (not less than 5\%) of the GOST requirements (minimum diameter of $4 \mathrm{~cm}$ ) and made up: Sample F1-6\%, Favorita F1-7.2\%, Sharlotta F1-8.6\%, Garem F1- 6,1\%, Kalash F1-9.6\%, Azov F1-13,8, Beysuzhok F1-10.9\%, Salakhutdin F1-8.6\%.

Fresh tomato quality is a complex characteristic involving firmness besides physical appearance, as well as flavor and nutritive value. Concentrations of dry matter, soluble solids, titratable acidity, volatile compounds, minerals, carotene and vitamin $\mathrm{C}$ in fresh fruit increase with increasing salinity (Tuzel et al., 2001; Dorais et al., 2000; Sonneveld and Welles, 1988; Stevens, 1979).

Consumer tests have indicated that hardness and aroma are important criteria for high-quality tomatoes, where typical tomato aroma depends on the relation between sugar and acid (Vesseur, 1990). Higher sugar and organic content of acid improves the quality of tomatoes (Davies and Hobson, 1981).

The experimental data of biochemical analysis revealed that the overall acidity of the studied hybrid fruit was at the same level. The greatest amount of dry matter, sugar and ascorbic acid contained in the fruits of a standard sample Francesca F1 and the Dutch selection hybrids. These hybrid fruits had a very good taste.

The Russian selection hybrids had the minimum parameters of dry matter, sugar and ascorbic acid. The fruits of these hybrids were less attractive and were inferior to other hybrids both in habit and in taste.

The content of nitrate ions in the fruits of all the studied hybrids was approximately at the same level and far below the maximum permissible concentration (300 mg kg-1).

Choosing a hybrid is a major factor in determining the profitability of production, the system of cultivation, energy and other production costs. Productivity is closely related to a varietal traits of culture (Avdeenko, 2005).

The studies have shown that the profit gained from the greenhouse tomato cultivation depends on their high yield and uniform yield return during the growing season.

According to cost-effectiveness analysis, only Dutch selection hybrids, with the highest yield from 21.85 to
$27.30 \mathrm{~kg} / \mathrm{m}^{2}$ during the period of studies, made it possible to make a profit.

The largest profit was obtained from sales of Panekra F1 fruit hybrids, with the highest yield and of Clarabella F1, with the most uniform yield return. Indicators of the cost-effectiveness of these hybrids were higher than the standard sample: In profit - by 19.3 and $2.6 \%$ and in profitability - by 4.9 and $0.7 \%$, respectively. The size of the profit of the rest of the Dutch selection hybrids provided the break-even of production from $0.2 \%$ (a hybrid of Sample F1) to 16.3\% (a hybrid Esmira F1), although it was lower than that of the standard sample. Cultivation of the Israeli and Russian selection hybrids was carried out at a loss.

\section{Conclusion}

The test results of various hybrids of tomatoes in soilless culture cultivation greenhouses in the conditions of the 7-photic zone of the pre-Aral area showed that the best results in terms of yield and fruit quality were obtained from hybrids from the Dutch selection.

The most productive amongst them was a hybrid Panekra F1, with a yield of $27.30 \mathrm{~kg} / \mathrm{m}^{2}$. The hybrid had the highest yield of standard products - $97.9 \%$ - and its fruit had a very good taste. This is the only hybrid to have exceeded the standard sample Francesca F1 on all indicators.

Hybrids Lilos F1, Maxitos F1, Gravitet F1, Klepton F1, Esmira F1 and Clarabella F1 also made it possible to get high yield and fruit quality. Their yield was $23.86-26.13 \mathrm{~m}$ $\mathrm{kg} / \mathrm{m}^{2}$, that is $91.2-100 \%$ with respect to the standard sample. These hybrids had a high yield of standard products-95.6-97.8\% - and fruits with an excellent taste.

As a result of the study it was noted that the profit from the sale of products was determined not only by high productivity, but by the uniformity of the yield return during the growing season.

The largest profit was made by growing hybrids Panekra F1 and Clarabella F1. The break-even level made up 29.6 and About 25.4\%, that is 4.9 and $0.7 \%$ higher than that of the standard sample. Moreover, relatively high profit was obtained from the cultivation of hybrids Lilos F1, Maxitos F1, Gravitet F1, Klepton F1, Esmira F1 and Clarabella F1 and in this case the break-even level amounted 10.8-16.3\%.

These hybrids are recommended for soilless culture in greenhouses in the conditions of the 7-phobic zone of the pre-Aral area.

\section{Acknowledgment}

The authors would like to express their gratitude towards the staff of the Korkyt Ata Kyzylorda State University greenhouses for assisting in the experimentation, cultivation and yield management, as well as towards the company "Rijk Zwaan" (Almaty) and "Gavrish" (Moscow) for the tomato hybrid testing seeds provided. 


\section{Funding Information}

This work was performed within the framework of the program of the Ministry of Education and Science of the Republic of Kazakhstan "Grant financing for research" on priority "Life Science".

\section{Author's Contribution}

Rakhym Iskendirovich Kudiyarov and Igor Aleksandrovich Bobrenko: Provided leadership and coordinated the implementation of research work, analyzed and interpreted the study findings, drew conclusions.

Elina Bakhtiyarovna Dyamurshayeva, Gulsym Zykriyaevna Sauytbayeva and Galina Evgenyevna Dyamurshayeva: Conducted research, compiled the literary review, analyzed and interpreted the results, edited tables and drawings, printed the text and wrote the conclusion according to the tables.

Nurlan Zhetkergenovich Urazbayev: Made calculations on cost-effectiveness, interpreted the results obtained and drew conclusions.

Salima Izbaskanovna Sadybekova: Translated the text into English, performed all the technical and organizational work.

\section{Ethics}

This article is original and contains unpublished material. The corresponding author confirms that all of the other authors have read and approved the manuscript and no ethical issues involved.

\section{References}

Amarananjundeshwara, H., S. Shyamalamma, V. Chikkasubbanna and M.Y. Ajayakumar, 2008. Performance of tomato hybrids under greenhouse conditions. Mysore J. Agric. Sci., 42: 617-620.

Avdeenko, S.S., 2005. Assessment of hybrids of tomatoes for plastic greenhouses. Achievements Modern Nat. Sci., 11: 46-47.

Bakulina, V.A., 1988. Variety-technology background. Potatoes Vegetables, Moscow, 1: 14-20.

Bakulina, V.A., 1996. Varieties and hybrids of vegetables for cultivation in the protected ground. Gavrish, 3: 4-8.

Balashov, E.S., 2006. Features of growth and development of new tomato hybrids under cultivation in the extended cycle of winter glazed greenhouse. PhD Thesis, All-Russian Research Institute of Vegetable Growing, Moscow.

Barabash, O.Y. and V. Kravchenko, 2012. Modern Vegeculture of the Protected and Open Ground: Practice Guidelines. 1st Edn., PC "Ruta”, Kiev, pp: 18.
Becherescu, A., A. Horgoș, D. Popa, G. Hoza and A. Ienciu, 2015. Study on the impact of culture substratum and fertilization system upon the productive potential of some tomato hybrids cultivated in industrial greenhouses. J. Horticulture, Forestry Biotechnol., 19: 52-58.

Belik, V.F., 1992. Methodology of Experimental Work in the Vegetable and Melon Growing. 1st Edn., Agropromizdat, Moscow, pp: 319.

Brovko, G.A., 2006. Agrobiological justification of resource-saving technology of cultivation of a cucumber and tomato in winter greenhouses of the Far East. PhD Thesis, All-Russian Research Institute of Vegetable Growing, Moscow.

Davies, J.N. and G.E. Hobson, 1981. The constituents of tomato fruit-the influence of environment, nutrition and genotype. CRC Critical Rev. Food Sci. Nut., 15: 205-280. DOI: 10.1080/10408398109527317

Dhaliwal, M.S. and K.S. Nandpuri, 1988. Genetics of yield and its components in tomato. Ann. Biol., 4: 75-80.

Dorais, M., R. Dorval, D.A. Demers, D. Micevic and G. Turcotte et al., 2000. Improving tomato fruit quality by increasing salinity: Effects on ion uptake, growth and yield. Acta Horticulturae, 511: 1109-1100. DOI: 10.17660/ActaHortic.2000.511.21

Dorais, M., C. Menard and E. Begin, 2007. Risk of phytotoxicity of sawdust substrates for greenhouse vegetables. Acta Horticulturae, 761: 589-594. DOI: 10.17660/ActaHortic.2007.761.82

Dorais, M., A. Papadopoulos and A. Gosselin, 2001. Greenhouse tomato fruit quality. Horticultural Rev., 26: 239-319. DOI: 10.1002/9780470650806.ch5

Dospechov, B.A., 1979. Methods of Field Experience. 1st Edn., Kolos, Moscow, pp: 271.

Ehret, D.L. and T. Helmer, 2009. A new wood fibre substrate for hydroponic tomato and pepper crops. Canad. J. Plant Sci., 89: 1127-1132. DOI: $10.4141 /$ CJPS08183

Gavrish, S.F., 2015. Modern hybrids tomato and cucumber. Gavrish, 4: 2-5.

GOST ISO 750-2013. Fruit and vegetable products. Determination of Titratable Acidity.

GOST 8756.13-87. Fruit and vegetable products. Methods for Determination of Sugar.

GOST 24556-89. Products of fruits and vegetables processing. Methods for Determination of Vitamin C.

GOST ISO 2173-2013. Fruit and vegetable products. Refractometric Method for Determination of Soluble Solids Content.

GOST 1725-85. Tomatoes, fresh. Technical Conditions.

GOST 29270-95. Fruit and vegetable products. Methods for Determination of Nitrates.

Gruda, N. and W.H. Schnitzler, 2004. Suitability of wood fiber substrate for production of vegetable transplants: I. Physical properties of wood fiber substrates. Sci. Horticulturae, 100: 309-322. DOI: $10.1016 /$ j.scienta.2003.10.001 
Hochmuth, G.J., 2015. Production of greenhouse tomatoes-Florida greenhouse vegetable production handbook, University of Florida.

Hussain, S.I., K.M. Khokhar and K.M. Qureshi, 1990. Variety trial on green house tomatoes grown under un-heated plastic tunnel. Pak. J. Agric. Sci., 27: 248-251.

Hussain, S.I., K.M. Khokhar, T. Mahmood, M.H. Laghari and M.M. Mahmud, 2001. Yield potential of some exotic and local tomato cultivars grown for summer production. Pak. J. Biol. Sci., 4: 1215-1216.

DOI: $10.3923 /$ pjbs.2001.1215.1216

Jensen, M., 1997. Food Production in Greenhouses. In: Plant Production in Closed Ecosystems: The International Symposium on Plant Production in Closed Ecosystems. Springer Science and Business Media, Dordrecht, ISBN-10: 9401588899, pp: 1-14.

Kiry, P.I., 2007. Improving the technology of tomato cultivation in the extended cycle of the winter block greenhouse of the fourth photic zone. PhD Thesis, All-Russian Research Institute of Vegetable Growing, Moscow.

Korol, V.G., 2000. Criterion for variety selection. Gavrish, 3: 3-4.

Korol, V.G., 2011. Agrobiological basis for productivity enhancement of vegetables in the winter greenhouse. PhD Thesis, All-Russian Research Institute of Vegetable Growing, Moscow.

Lutsenko, N.E., 2002. Prospects for growing tomatoes indoors on small-volume hydroponics technology. Polythematic Network Electronic Scientific Magazine of the Kuban State Agricultural University.

Olericulture, 2001. Canada, Alberta. 1st Edn., Olds College, pp: 47.

Rajasekar, M., T. Arumugam 1 and S. Ramesh Kumar, 2013. Influence of weather and growing environment on vegetable growth and yield. J. Horticulture Forestry, 5: 160-167.

Reddy, M.T., S. Ismail and Y.N. Reddy, 1999. Shade and allelopathic effects of ber on growth, productivity and quality of radish (Raphanus Sativus L.) under pot culture. South Indian Horticult., 47: 77-80.

Rodica, S., S.A. Apahidean, M. Apahidean, D. Maniuțiu and L. Paulette, 2015. Yield, physical and chemical characteristics of greenhouse tomato grown on soil and organic substratum. Proceedings of the $3 \mathrm{rd}$ International Symposium on Agriculture, (ISA' 15), pp: 439-443.
Shevelukha, B.C., 1992. Plant Growth and its Ontogenesis Regulation. 1st Edn., Kolos, Moscow, pp: 598.

Sonneveld, C. and G.W.H. Welles, 1988. Yield and quality of Rockwool-grown tomatoes as affected by variations in EC-value and climatic conditions. Plant Soil, 111: 37-42. DOI: 10.1007/BF02182034

Stevens, M.A., 1979. Tomato quality: Potential for developing cultivars with improved flavor. Acta Horticulturae, 93: 317-329. DOI: 10.17660/ActaHortic. 1979.93.30

Singh, B., M. Kumar and M. Hasan, 2006. Performance of tomato cultivars under greenhouse conditions in Northern India. J. Vegetable Sci., 11: 73-80. DOI: $10.1300 / J 484 v 11 n 0407$

Singh, R.P. and S. Singh, 1985. Detection and estimation of components of genetic variation for some metric traits in tomato (Lycopersicon esculentum Mill). Theor. Applied Genet., 70: 80-84. PMID: 24254118

Singh, S., V.B. Pandey, D.R. Singh and R.C. Srivastava, 2009. Evaluation of tomato cultivars under protected conditions in Bay island conditions. Proceedings of the National Seminar on Production System Management in Adverse Condition for Higher Productivity in A \& N Islands, Dec. 22-24, India.

Singh, T., N. Singh, A. Bahuguna, M. Nautiyal and V.K. Sharma, 2014. Performance of tomato (Solanum lycopersicum L.) hybrids for growth, yield and quality inside polyhouse under mid hill condition of uttarakhand. Am. J. Drug Discovery Dev., 4: 202-209. DOI: 10.3923/ajdd.2014.202.209

Singh, U.P., I. Tanki and R.K. Singh, 1989. Studies on order effect and epistatic components for yield in double cross hybrids of tomato. Haryana J. Hort. Sci., 18: 265-271.

Tarakanov, G.I., 1997. Variety - key link of technology. Greenhouse Land, 6: 8-10.

Tuzel, J.H., Y. Tuzel, A. Sul and R.Z. Elterz, 2001. Effects of EC level of the nutrient solution on yield and fruit quality of tomatoes. Acta Horticulturae, 559: 587-592. DOI: 10.17660/ActaHortic.2001.559.86

Vesseur, W.P., 1990. Tomato tasting and consumer attitude. Acta Horticulturae, 259: 83-89.

DOI: 10.17660/ActaHortic. 1990.259.7

Zdravković, J., N.V. Pavlović, Z. Girek and A.D. Cvikić, 2011. Generation mean analysis of yield components and yield in tomato (Lycopersicon esculentum Mill.). Pak. J. Bot., 43: 1575-1580. 